\title{
STRUCTURE OF LIQUID SILICATE SLAGS
}

\begin{abstract}
T HE investigation of steol-making slags goes back probably to the 1880's when Fouqué and Lévy experimented with synthetic minerals made from fusion of pure oxides at controlled temperatures. Later, Doelter, Vogt and Tammann carried the work a stage further in their investigations of silicate phase-diagrams. The work of Rankin, Wright and Bowen at the Goophysical Laboratory in Washington, on binary and ternary silicate phasediagrams, is well known and contributed much to our knowledge of composition and structure of metallurgical slags. It was otherwise, however, with liquid silicates, the 'magma' from which minerals in solid slags crystallized out. This complex problem appears to have been investigated by Vogt in 1902, but his conclusion that the crystalline minerals found microscopically in a slag ropresonted those fundamental to tho mother-liquor was later disproved by Schenck in the 1930's. Schenck's thesis was that knowledge of the crystallized compounds found in slags was of little value as a guide to their behaviour in the liquid state. The concentration of oxides of lime, iron and silica in a slag gives no clear indication of its chemical properties because of the ramified chemical changes occurring when they react to form a solution. Later work by Sauerwald and Nouendorff in 1925 demon. strated the ionie nature of liquid silicates by causing deposition of metallic iron from an iron-silicate melt by electrolysis.

In $\mathbf{a}$ stimulating article by J. B. Henderson of the Department of Physical Chemistry, Central Research Laboratories, the Broken Hill Proprietary Co., Ltd., Australia (Technical Bulletin, 7, No. 2; July 1963), the present-day theories of the constitution of liquid silicate slags are reviewed and their limitations clearly defined. Although brief, this article gives an indication of the technique now being appliod in contemporary studies in the elucidation of the structure of the more complex silicate slags. Henderson comments: "Until recently little inter.
\end{abstract}

est has boen evinced in these liquids. There are two reasons for this: in the first place, it has been exceedingly difficult to study these melts under well-controlled conditions in the laboratory, owing to the lack of good refractories and the tiresome techniques involved. In the second, these liquids are themselves so complex that theoretical prediction of their structure has so far proved impossible".

Such knowledge as we have to-day of liquid silicatos is essentially founded on the X-ray results of researches by Zachariasen, Bragg and Biscoe and Warren (see F. D. Richardson, "Oxide Slags--A Survey of Our Present Knowledge", The Physical Chemistry of Steel-Making, 55, John Wiley and Sons, and Technology Press, New York, 1958). In his article Mr. Henderson reviews some of the modern ideas of liquid silicate structure and shows how such models are derived by reference to "measurements of self-diffusion coefficients". He contrasts by schematic representation (after Richardson) the silicate tetrahedron which is fundamental and the molten silica pattern in which the structure is distorted. The addition of metal oxides, such as lime or magnesia, to the molten silica produces profound structural changes which are indicative of the electrochemical forces at work.

The complexity of this problem of the constitution of liquid silicatos is here clearly demonstrated. Present-day theories may help to explain 'qualitatively' the nature of binary melts, but 'quantitatively' they cannot be de. seribed nor can the structure of melts of more complicated compositions be predicted. These demand individual investigation and many different types of measurement are needed. The approaches to such research now in train in the Broken Hill Proprietary Company's Laboratories include X-ray, neutron and electron diffraction, absorption spectroscopy, electrolysis, ultra-sonic absorption, density, cryoscopy, refractive index and vapour pressure.

H. B. Miluner

\section{FIBRE OPTICAL PROPERTIES OF ULEXITE}

\author{
By Mrs. E. J. WEICHEL-MOORE and LR. R. J. POTTER \\ Thomas J. Watson Research Center, Yorktown Heights, New York
}

\begin{abstract}
$\mathrm{T}$ HE optical fibre bundle, now a commercially available optical component, requires very high precision in manufacture. It is essential that the optical fibres be assembled in a carefully controlled array such that the position of each fibre with respect to the others is maintained. In many cases, there are hundreds of millions of individual fibres in a given bundle. The manufacture, insulation and assembly of optical fibres are major technological problems which have been overcome by a number of manufacturers.

The early published work on fibre optics by Baird ${ }^{1}$, Hansell ${ }^{2}$, and Lamm $^{3}$ described devices for transmitting images with bundles of bare glass fibres.

In the early 1950's, fibre optics was essentially rediscovered by A. C. S. van Heel ${ }^{4,5}$, H. H. Hopkins ${ }^{6}$ and Brian O'Brien?. Their work is important in the development of the technology. They realized the need for optical insulation, that is, low index cladding betweon the fibre cores in a close-packed structure.
\end{abstract}

Since that time, much has been published on the properties of clad optical fibres and the applications of clad fibre bundles. It is significant, howovor, to note that virtually no important application of fibre optics without cladding has survived. Actually, the technique of assembling and drawing glass fibre bundles was developed by glassmakers in Palestin $\theta^{8}$ in the first century B.c. They assembled fibres of coloured glass in the form of a portrait, fused the fibres together, and drew the resulting rod to reduce the portrait in size. The rods were then cut into cross-sections, polished, and pierced to be used as beads. We thank Dr. Dietrich von Bothmer, curator of the Greek and Roman Department of the Metropolitan Museum of Art in Now York City, for his co-operation in affording several of theso ancient beads for microscopic examination; they were found to be remarkably well preserved. The glasses of which the beads were made are mostly opaque in the bead thickness of approximately $\frac{1}{8}$ in. $\times \frac{1}{4}$ in. The fibre structure was eliminated in the 